Supporting Information

for

\title{
High-Index (Ni,Mg)O Crystallization during Molten Salt Synthesis
}

\author{
Mariano D. Susman,§ Sivadinarayana Chinta,\# Jeffrey D. Rimer §,* \\ $\S$ Department of Chemical and Biomolecular Engineering, University of Houston, 4726 Calhoun \\ Road, Houston, Texas 77204, USA \\ \# SABIC Technology Center, 1600 Industrial Blvd. Sugar Land, Houston, TX 77478, USA \\ *Correspondence sent to: jrimer@central.uh.edu
}

\section{List of Supporting Figures and Schemes}

Figure S1. Photographs of $\mathrm{NiO}-\mathrm{MgO}$ samples prepared by $\mathrm{MSS}$ in $\mathrm{NaCl} / \mathrm{KCl}$ and $\mathrm{NaNO}_{3} / \mathrm{KNO}_{3}$ $(1: 1)$.

Figure S2. Optical microscopy images of $\mathrm{NiO}-\mathrm{MgO}$ materials with a $\mathrm{Mg} / \mathrm{Ni}$ ratio of 4:1.

Figure S3. SEM/EDS-derived $\mathrm{Mg} / \mathrm{Ni}$ ratios at various locations in single-crystalline particles.

Figure S4. Particle edge distributions of selected (Ni,Mg)O and $\mathrm{NiO}-\mathrm{MgO}$ materials.

Figure S5. Rietveld refinement profiles of $(\mathrm{Ni}, \mathrm{Mg}) \mathrm{O}$ solid solutions produced in $\mathrm{NaCl} / \mathrm{KCl}$ $(1: 1)$.

Figure S6. EDS mapping of oxides prepared with $\mathrm{Mg} / \mathrm{Ni}=4: 1$ and $1: 4$ in $\mathrm{NaCl} / \mathrm{KCl}$ and $\mathrm{NaNO}_{3} / \mathrm{KNO}_{3}$.

Figure S7. EDS spot analyses of oxides prepared using a $\mathrm{Mg} / \mathrm{Ni}$ ratio of $4: 1$

Figure S8. PXRD patterns of $(\mathrm{Mg}, \mathrm{Ni}) \mathrm{O}$ produced in $\mathrm{KCl}$ and $\mathrm{NaCl}$, and segregated $\mathrm{NiO}-\mathrm{MgO}$ produced in $\mathrm{KNO}_{3}$ and $\mathrm{NaNO}_{3}$.

Figure S9. PXRD of $\mathrm{Mg}(\mathrm{II}) / \mathrm{Ni}(\mathrm{II})$ (1:1) nitrates decomposed in alkali chlorides and nitrates.

Figure S10. SEM images of oxides prepared from various synthesis mixtures.

Figure S11. PXRD patterns of $\mathrm{Mg}(\mathrm{II}) / \mathrm{Ni}(\mathrm{II})$ nitrate (1:1) mixtures in the presence and absence of $\mathrm{NaNO}_{3} / \mathrm{KNO}_{3}$.

Scheme S1. Proposed series of chemical reactions and phase transitions taking place in $\mathrm{NaCl} / \mathrm{KCl}$ (1:1) and $\mathrm{NaNO}_{3} / \mathrm{KNO}_{3}(1: 1)$ media. 

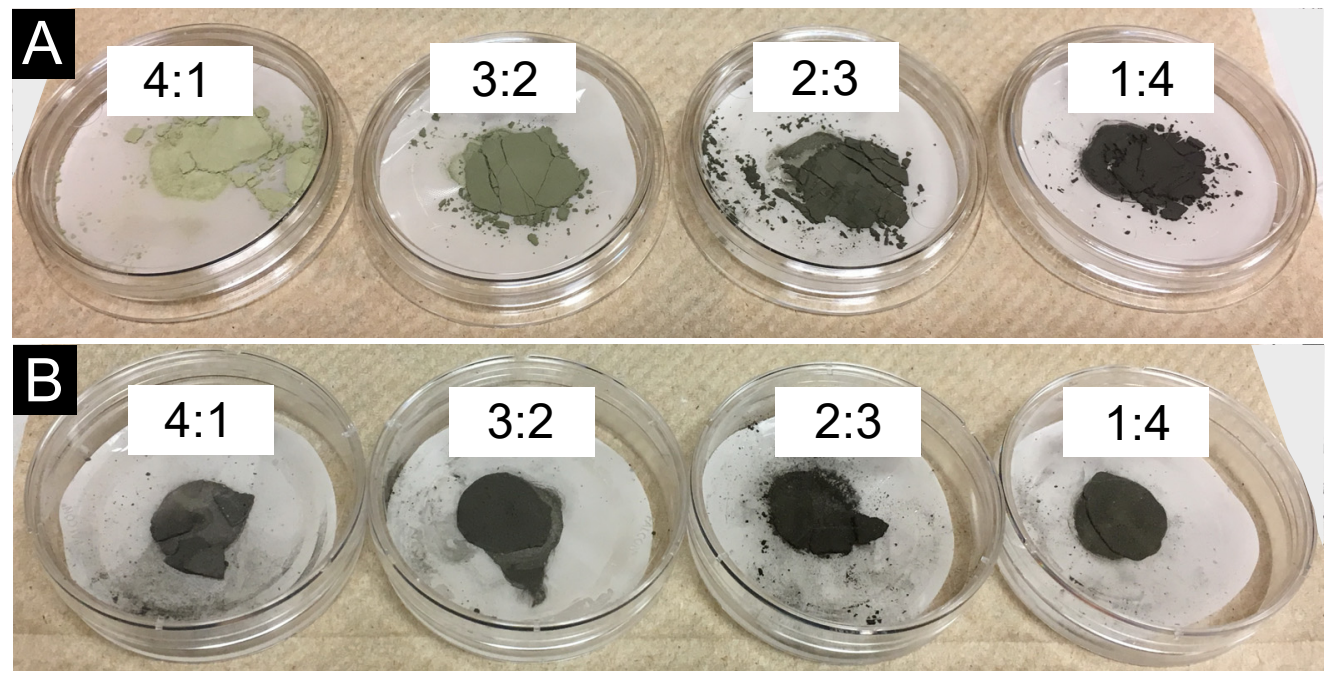

Figure S1. Photographs of NiO-MgO samples prepared by MSS in (A) $\mathrm{NaCl} / \mathrm{KCl}(1: 1)$ and (B) $\mathrm{NaNO}_{3} / \mathrm{KNO}_{3}(1: 1)$ using a total precursor-to-salt molar ratio of 1-to-10. Each sample was calcined at $550{ }^{\circ} \mathrm{C}$ for $1 \mathrm{~h}$ using a ramp rate of $2.5^{\circ} \mathrm{C} \mathrm{min}-1$. The $\mathrm{Mg} / \mathrm{Ni}$ nitrate precursor ratios are indicated.
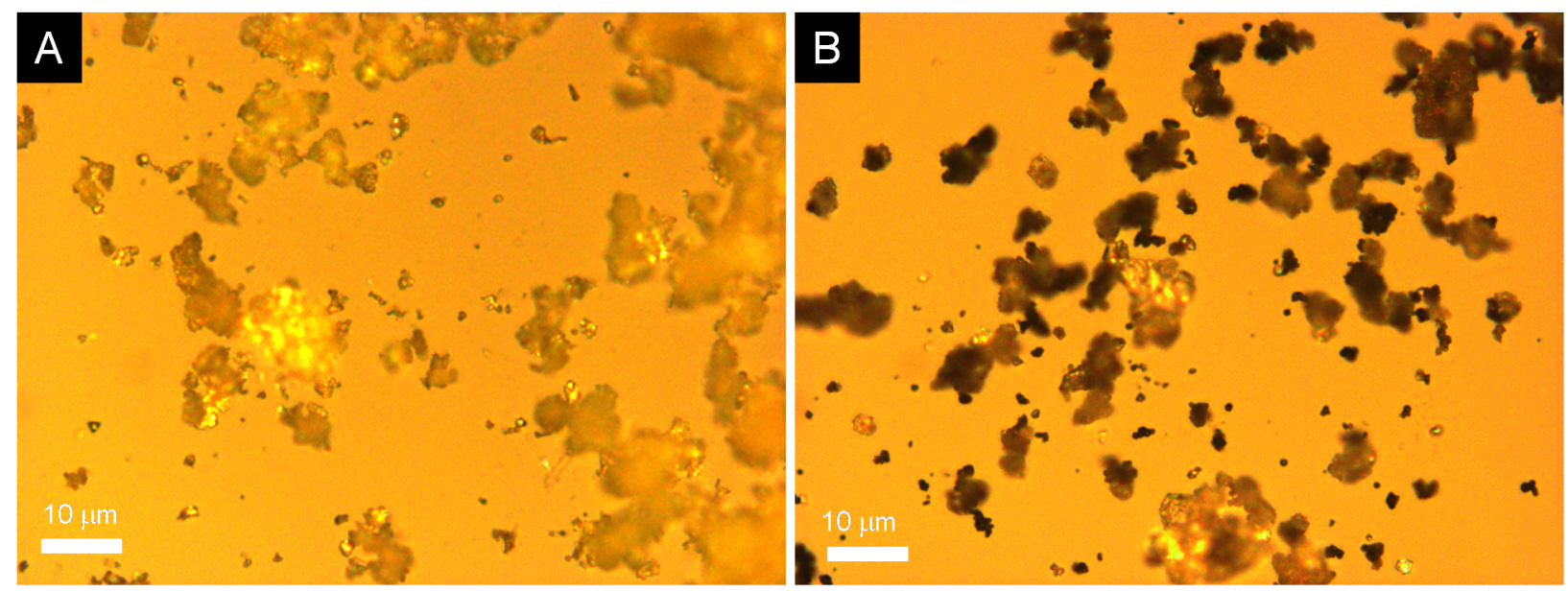

Figure S2. Optical microscopy images of $\mathrm{NiO}-\mathrm{MgO}$ with a $\mathrm{Mg} / \mathrm{Ni}$ ratio of $4: 1$. Samples were synthesized in (A) $\mathrm{NaCl} / \mathrm{KCl}(1: 1)$ and (B) $\mathrm{NaNO}_{3} / \mathrm{KNO}_{3}$ (1:1) and imaged under bright field illumination. 

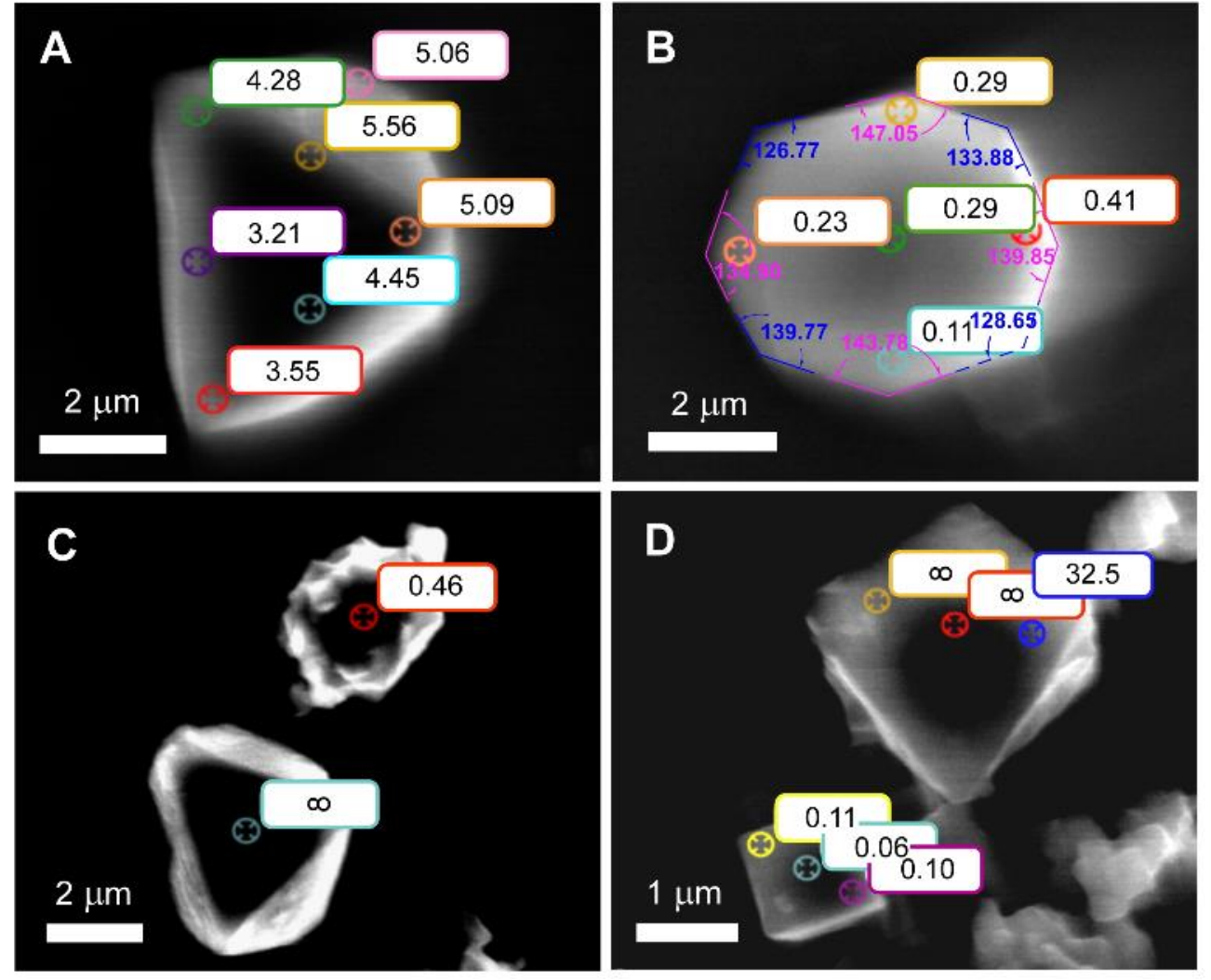

Figure S3. Mg/Ni ratios measured by SEM/EDS using spot analysis at various locations (indicated) within single-crystalline oxide particles produced in $(\mathrm{A}, \mathrm{B}) \mathrm{NaCl} / \mathrm{KCl}(1: 1)$ and $(\mathrm{C}, \mathrm{D}) \mathrm{NaNO}_{3} / \mathrm{KNO}_{3}(1: 1)$ media employing nominal $\mathrm{Mg} / \mathrm{Ni}$ ratios of (A,C) 4:1 and (B,D) 1:4. In panel (B), contour angles $\alpha$ (pink) and $\beta$ (blue) were measured for determining the high index associated with the exposed crystal facets. 

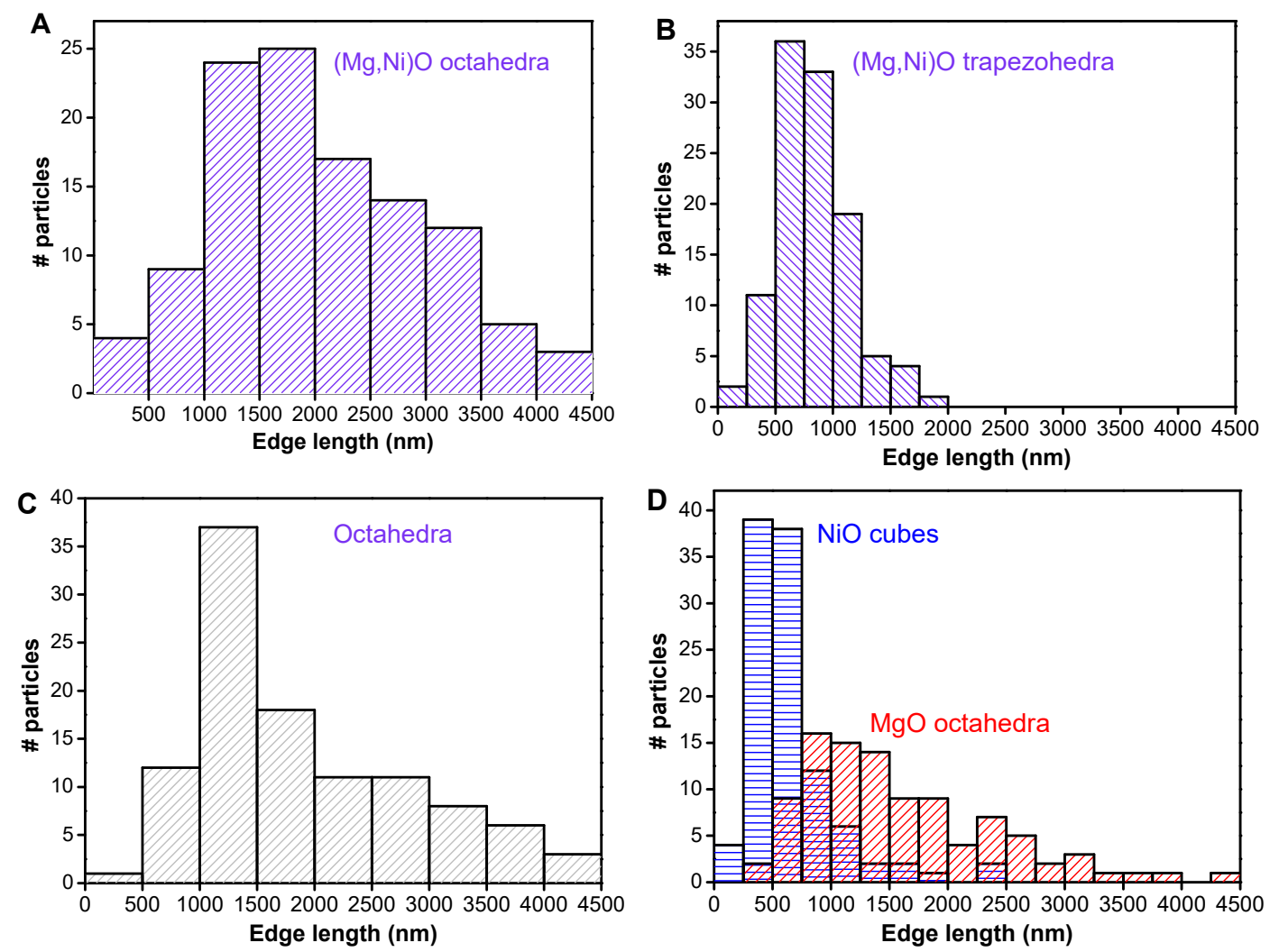

Figure S4. Particle size (edge length) distributions of crystals present in mixed oxides prepared in (A, B) $\mathrm{NaCl} / \mathrm{KCl}(1: 1)$ and (C,D) $\mathrm{NaNO}_{3} / \mathrm{KNO}_{3}$ (1:1) media with $\mathrm{Mg} / \mathrm{Ni}$ ratios of $(\mathrm{A}, \mathrm{C})$ 1:4 and (B,D) 4:1. For each set of data, more than 100 particles were measured. 

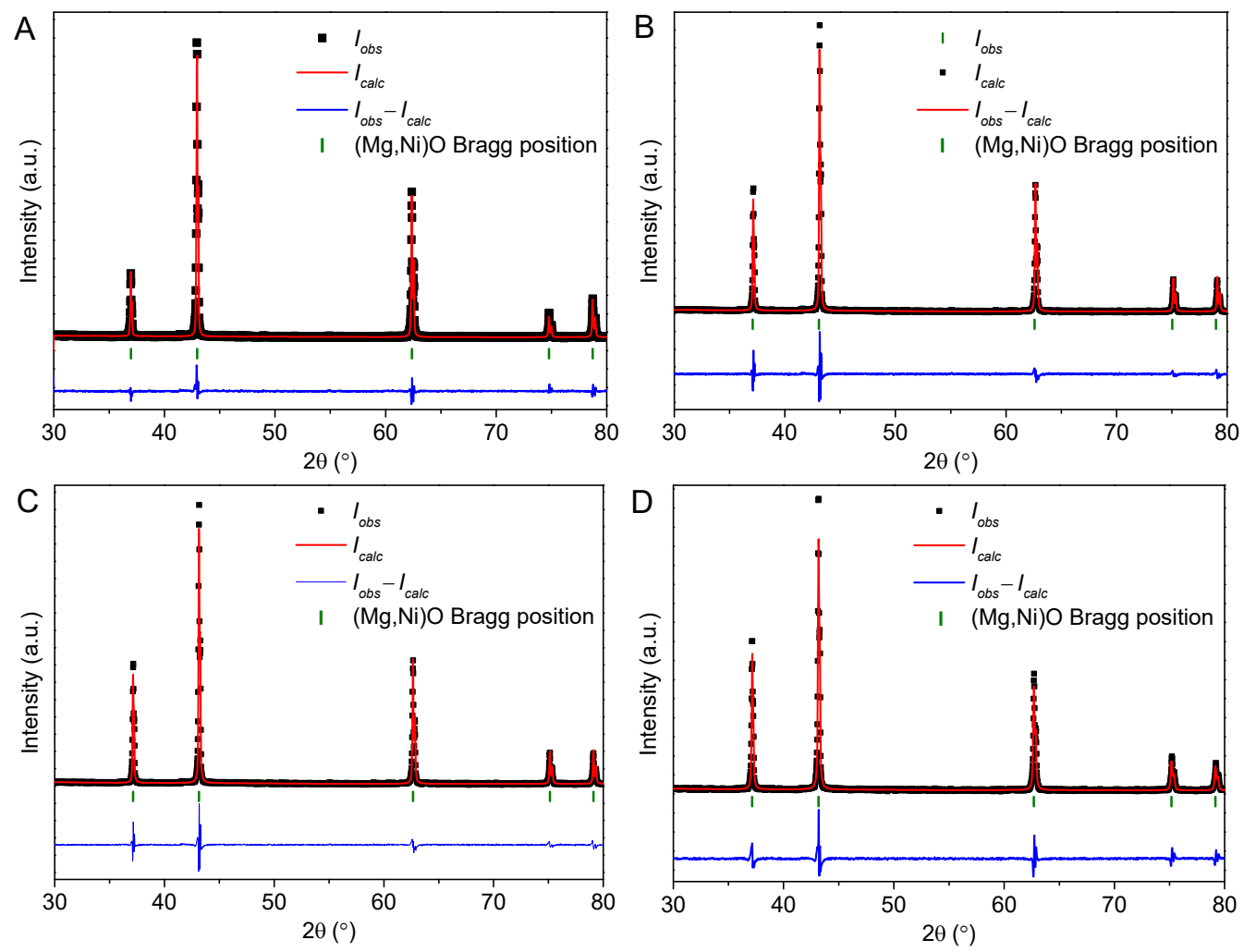

Figure S5. Rietveld refinement profiles of ( $\mathrm{Ni}, \mathrm{Mg}) \mathrm{O}$ solid solutions produced in $\mathrm{NaCl} / \mathrm{KCl}(1: 1)$ using $\mathrm{Mg} / \mathrm{Ni}$ ratios of (A) 4:1, (B) 3:2, (C) 2:3, and (D) 1:4. Observed data (black dots) along with calculated (red) and difference (blue) traces are indicated. Green ticks indicate calculated Bragg diffraction lines of the modelled mixed-oxide phases. 

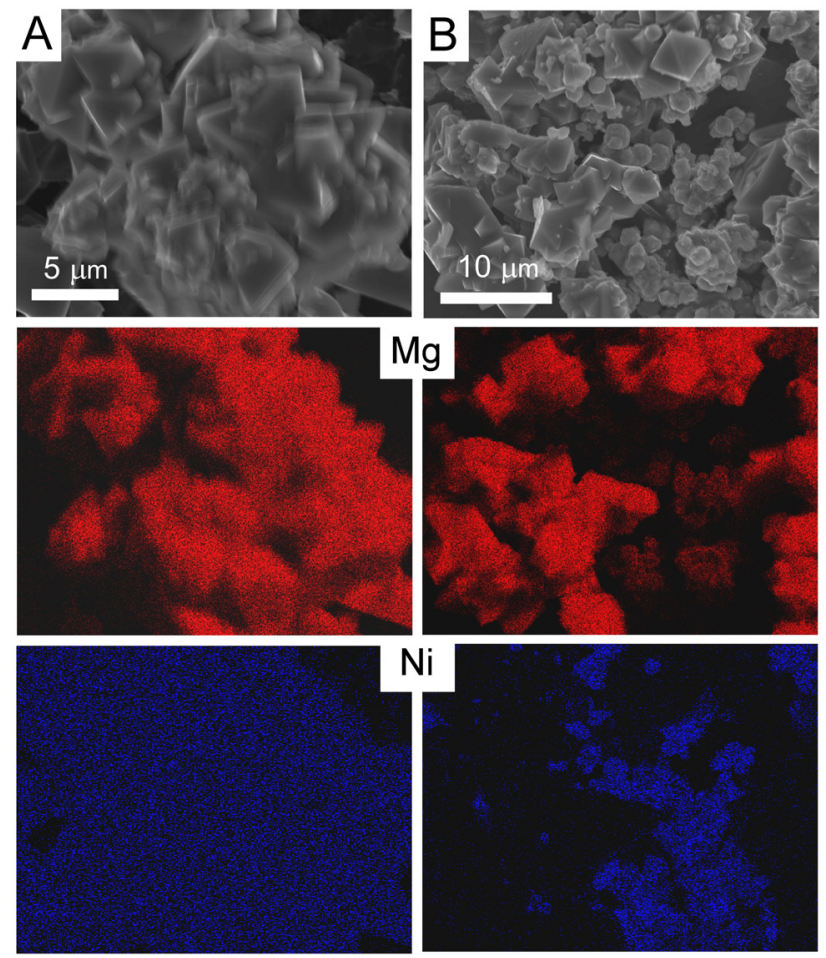

Figure S6. EDS elemental maps of mixed oxide samples prepared using a $\mathrm{Mg} / \mathrm{Ni}$ ratio of 4:1 in (A) $\mathrm{NaCl} / \mathrm{KCl}(1: 1)$ and (B) $\mathrm{NaNO}_{3} / \mathrm{KNO}_{3}(1: 1)$. 
A
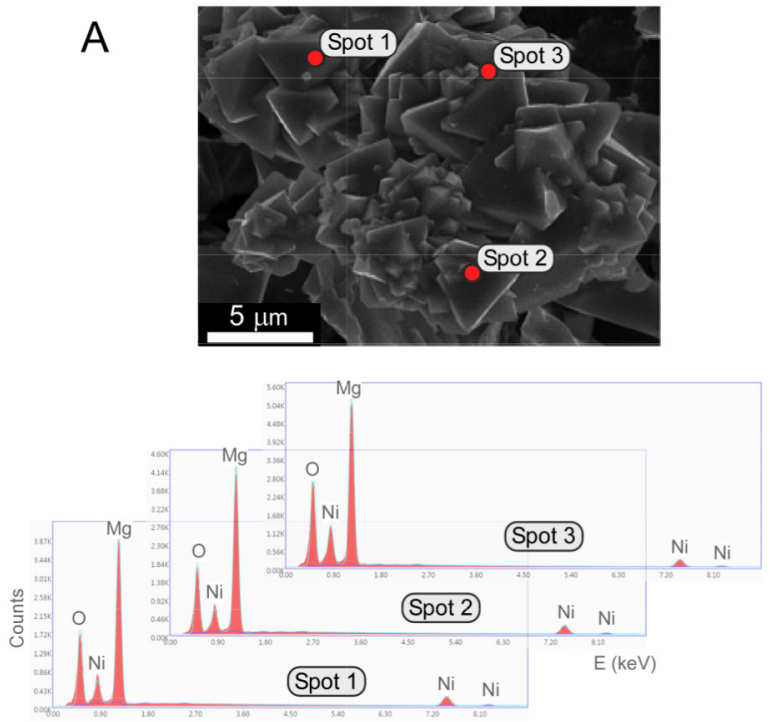

\section{C}
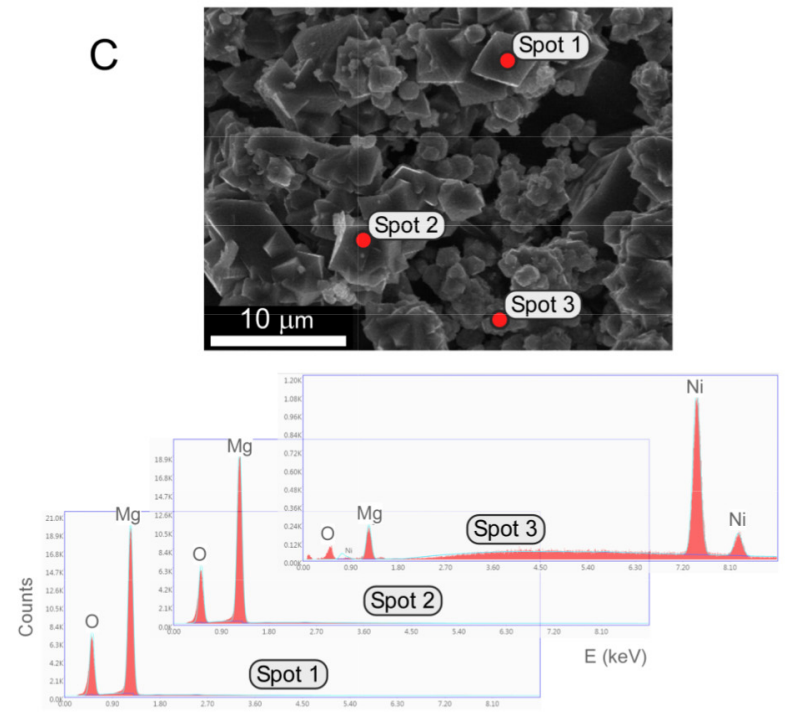

B
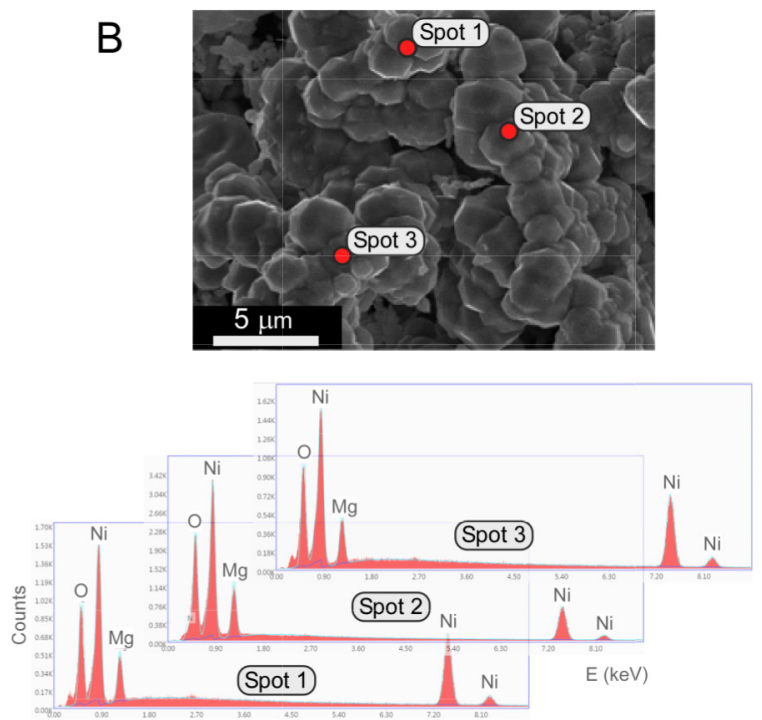

D
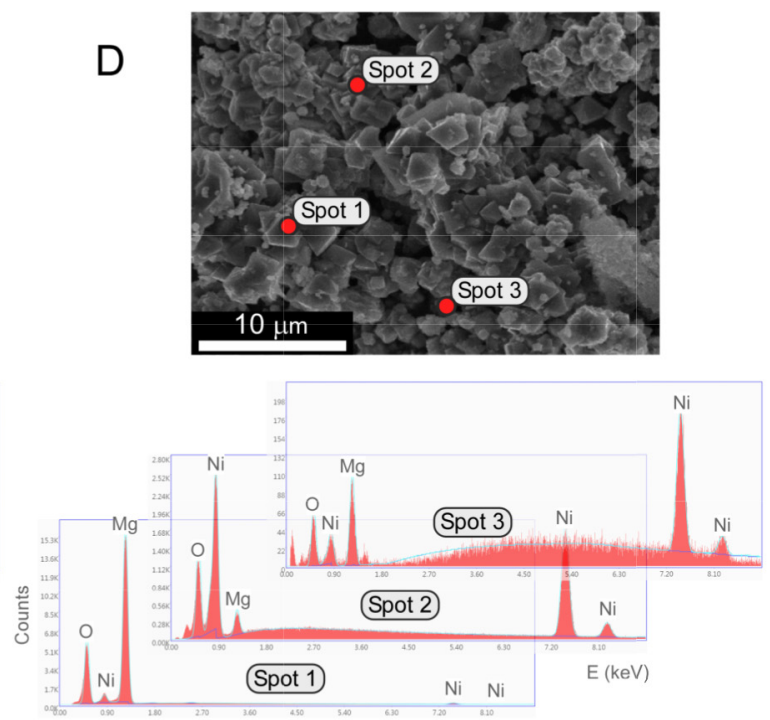

Figure S7. EDS Spot analysis (locations indicated in corresponding SEM images) of mixed oxide samples prepared using $\mathrm{Mg} / \mathrm{Ni}$ ratios of $(\mathrm{A}, \mathrm{C}) 4: 1$ and (B,D) 1:4 using the following media: $(\mathrm{A}, \mathrm{B}) \mathrm{NaCl} / \mathrm{KCl}(1: 1)$ and (C,D) $\mathrm{NaNO}_{3} / \mathrm{KNO}_{3}(1: 1)$. Emission spectra present signals for $\mathrm{Mg}\left(\mathrm{K} \alpha_{1}, \mathrm{~K} \alpha_{2}\right.$ and $\mathrm{K} \beta_{1}$ in the $1.25-$ $1.30 \mathrm{keV}$ range) and for $\mathrm{Ni}\left(\mathrm{L} \alpha_{1}, \mathrm{~L} \alpha_{2}\right.$ and $\mathrm{L} \beta_{1}$ in the $0.85-0.87 \mathrm{keV}$ range; $\mathrm{K} \alpha_{1}$ and $\mathrm{K} \alpha_{2}$ at $7.46-7.48 \mathrm{keV}$; and $\mathrm{K} \beta_{1}$ at $8.26 \mathrm{keV}$ ). 


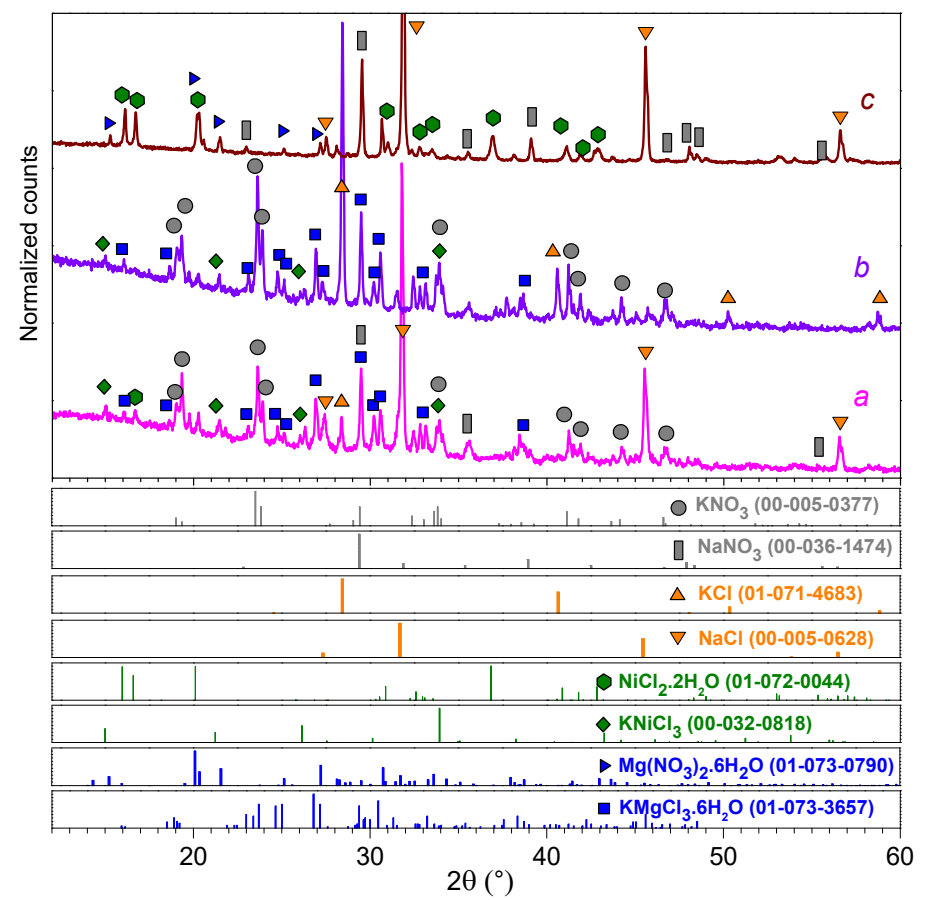

Figure S8. PXRD patterns of $\mathrm{Mg}\left(\mathrm{NO}_{3}\right)_{2} \cdot 6 \mathrm{H}_{2} \mathrm{O} / \mathrm{Ni}\left(\mathrm{NO}_{3}\right)_{2} \cdot 6 \mathrm{H}_{2} \mathrm{O}$ (1:1) mixtures in (a) $\mathrm{NaCl} / \mathrm{KCl}(1: 1)$, (b) $\mathrm{KCl}$, and (c) $\mathrm{NaCl}$. Measurements were made immediately after grinding. A precursor-to-medium molar ratio of 1:4 was used to increase the relative X-ray diffraction signal of the $\mathrm{Mg}$ (II) and $\mathrm{Ni}$ (II) phases with respect to the medium used.
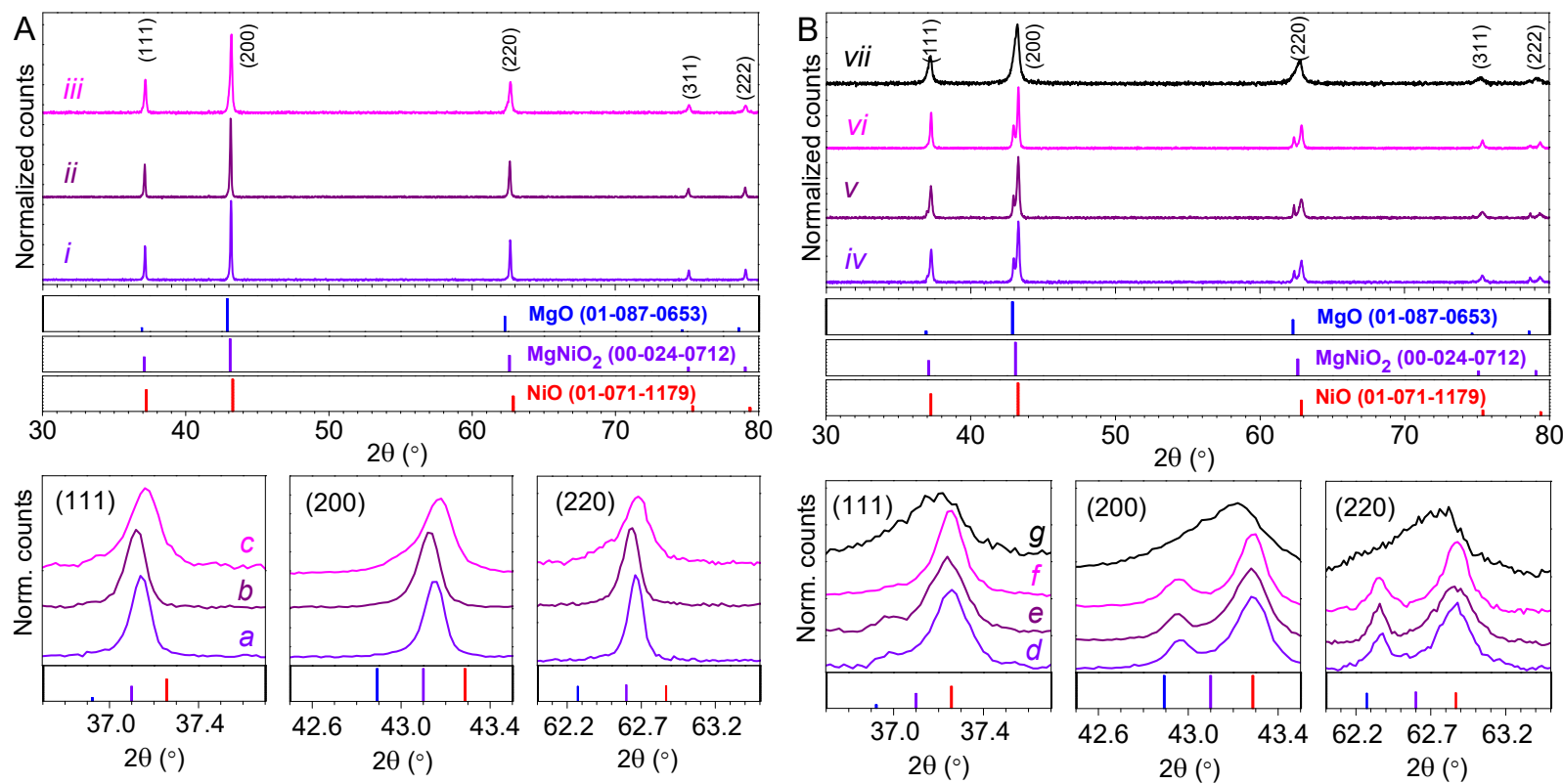

Figure S9. PXRD patterns of (A) (Mg,Ni)O produced in alkali chlorides (i) $\mathrm{NaCl} / \mathrm{KCl}(1: 1),($ ii $) \mathrm{KCl}$, and (iii) $\mathrm{NaCl}$; and (B) segregated $\mathrm{NiO}-\mathrm{MgO}$ produced in alkali nitrates (iv) $\mathrm{NaNO}_{3} / \mathrm{KNO}_{3}(1: 1),(v) \mathrm{KNO}_{3}$, and (vi) $\mathrm{NaNO}_{3}$. The pattern (vii) corresponds to a $\mathrm{Mg}\left(\mathrm{NO}_{3}\right)_{2} \cdot 6 \mathrm{H}_{2} \mathrm{O} / \mathrm{Ni}\left(\mathrm{NO}_{3}\right)_{2} \cdot 6 \mathrm{H}_{2} \mathrm{O}$ (1:1) blank decomposed in the absence of added salts. $\mathrm{A} \mathrm{Mg} / \mathrm{Ni}$ ratio of 1:1 was used in all cases ( $\mathrm{K} \alpha 2$ is removed for clarity). 

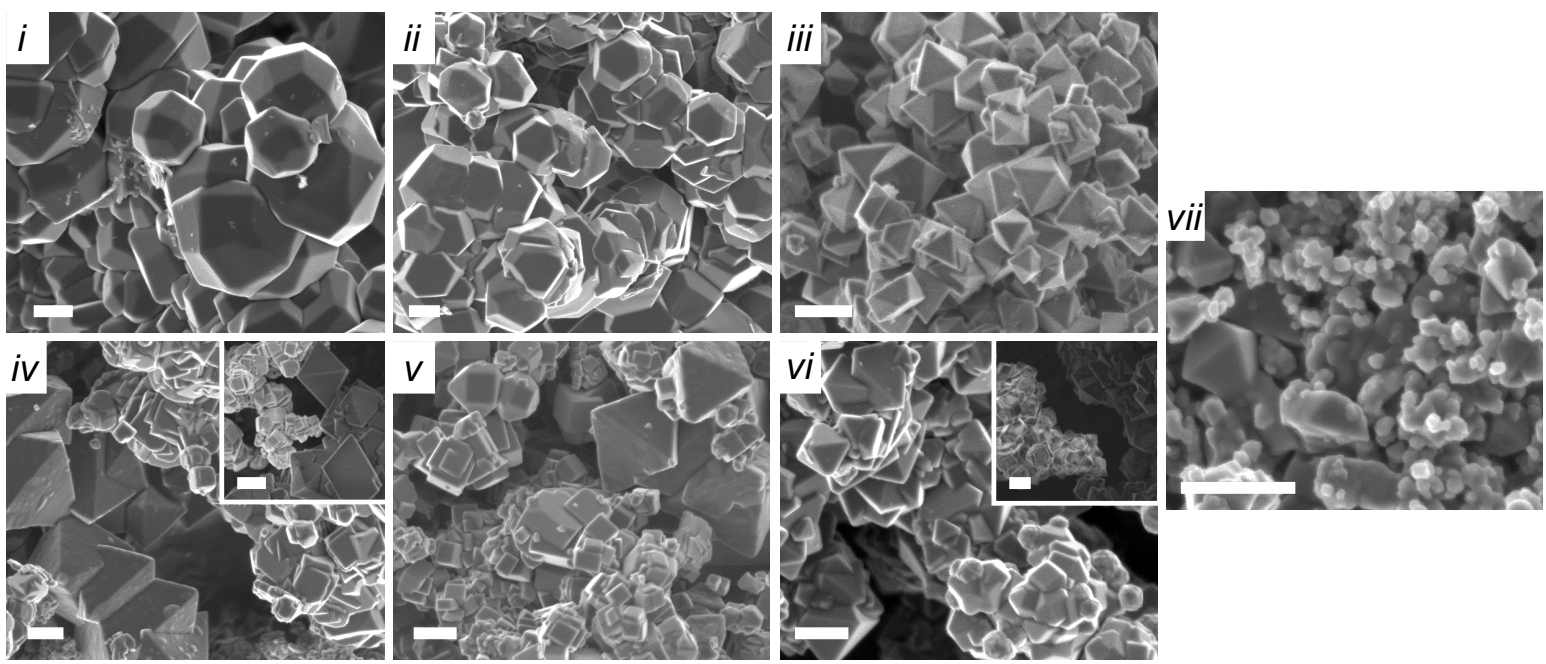

Figure S10. Scanning electron micrographs of $\mathrm{Mg} / \mathrm{Ni}(1: 1)$ samples presented in Figure $\mathrm{S}$. These samples were prepared by calcination in (i) $\mathrm{NaCl} / \mathrm{KCl}(1: 1)$, (ii) $\mathrm{KCl}$, (iii), $\mathrm{NaCl}$, (iv) $\mathrm{NaNO}_{3} / \mathrm{KNO}_{3}$ (1:1), (v) $\mathrm{KNO}_{3}$, (vii) $\mathrm{NaNO}_{3}$, and (vii) the absence of added salts. Insets show SEM images acquired without carbon coating showing different contrast between $\mathrm{MgO}$ - and NiO-rich domains. Scale-bars are equal to $1 \mu \mathrm{m}$. 

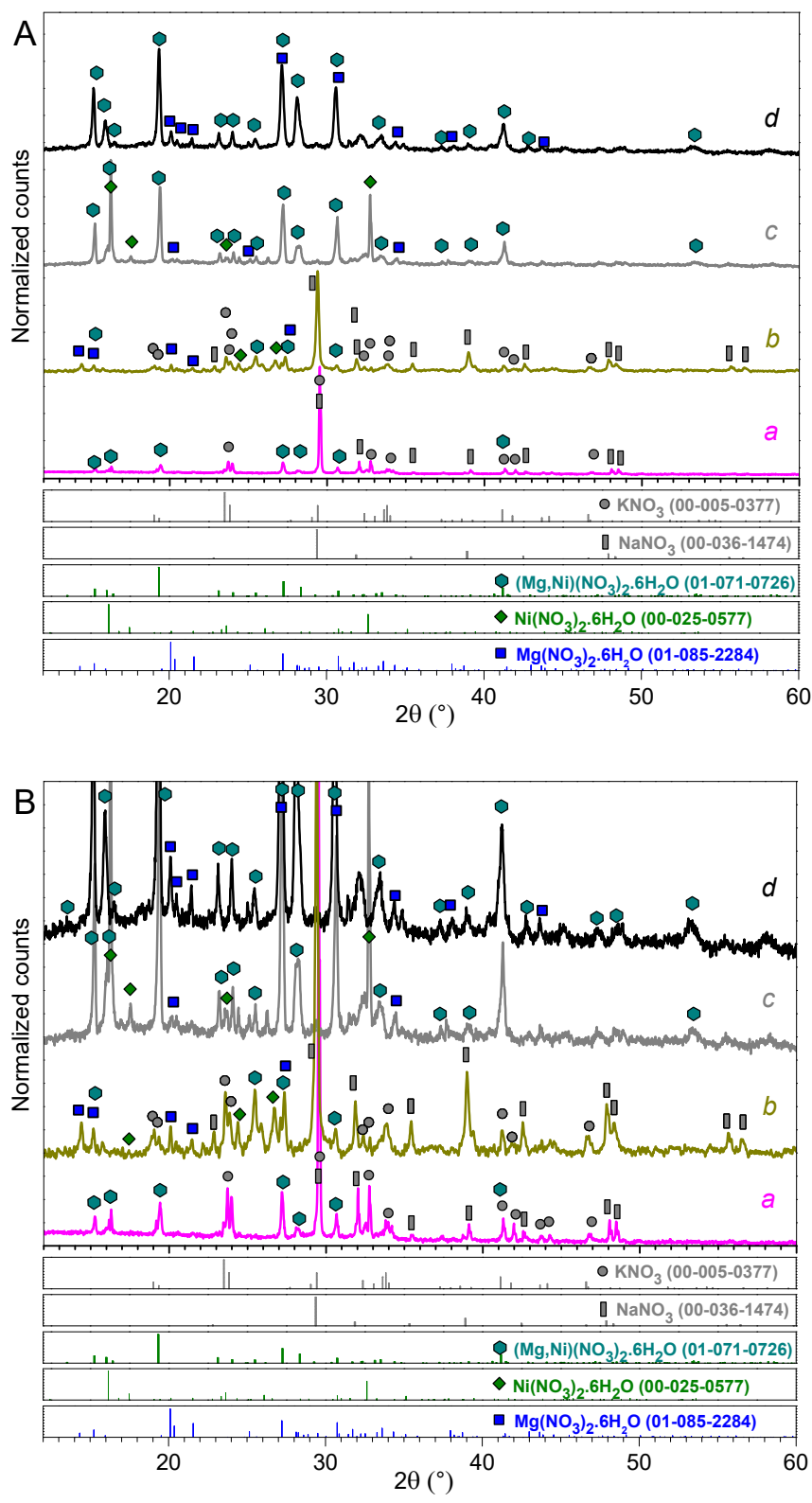

Figure S11. (A) PXRD patterns of $\mathrm{Mg}\left(\mathrm{NO}_{3}\right)_{2} \cdot 6 \mathrm{H}_{2} \mathrm{O} / \mathrm{Ni}\left(\mathrm{NO}_{3}\right)_{2} \cdot 6 \mathrm{H}_{2} \mathrm{O}(1: 1)$ mixtures in $(\mathrm{a}, \mathrm{b})$ the presence of a $\mathrm{NaNO}_{3} / \mathrm{KNO}_{3}(1: 1)$ medium under the following conditions: (a) right after grinding and (b) after grinding and thermal treatment at $300{ }^{\circ} \mathrm{C}$ for $5 \mathrm{~min}\left(\mathrm{ramp}\right.$ rate $\left.=2.5^{\circ} \mathrm{C} \mathrm{min}{ }^{-1}\right)$ to melt the system. A precursorto-medium ratio of 1:4 was used to increase the relative X-ray diffraction signal of the $\mathrm{Mg}$ (II) and $\mathrm{Ni}$ (II) phases with respect to the medium used. (c,d) Blanks in the absence of an alkali salt medium prepared by the following conditions: (c) right after grinding and (d) after thermal treatment at $100{ }^{\circ} \mathrm{C}$ for $5 \mathrm{~min}\left(2.5^{\circ} \mathrm{C}\right.$ $\left.\mathrm{min}^{-1}\right)$ to melt the system. (B) Enlarged version of panel A. The $(\mathrm{Mg}, \mathrm{Ni})\left(\mathrm{NO}_{3}\right)_{2} \cdot 6 \mathrm{H}_{2} \mathrm{O}$ reference corresponds to $\mathrm{Co}\left(\mathrm{NO}_{3}\right)_{2} \cdot 6 \mathrm{H}_{2} \mathrm{O}$ (ICDD 01-071-0726), which is a material reported to be isostructural. ${ }^{[1]}$ 
Scheme S1. Proposed series of chemical reactions and phase transitions taking place during grinding and MSS of $\mathrm{Mg}\left(\mathrm{NO}_{3}\right)_{2} \cdot 6 \mathrm{H}_{2} \mathrm{O} / \mathrm{Ni}\left(\mathrm{NO}_{3}\right)_{2} \cdot 6 \mathrm{H}_{2} \mathrm{O}$ mixtures in (A) $\mathrm{NaCl} / \mathrm{KCl}(1: 1)$ and (B) $\mathrm{NaNO}_{3} / \mathrm{KNO}_{3}(1: 1)$ salts. Orange element symbols indicate $\mathrm{Mg}(\mathrm{II})$ or $\mathrm{Ni}(\mathrm{II})$ likely having a coordination number of $\sim 6$, whereas green indicates a coordination number of $\sim 4$.

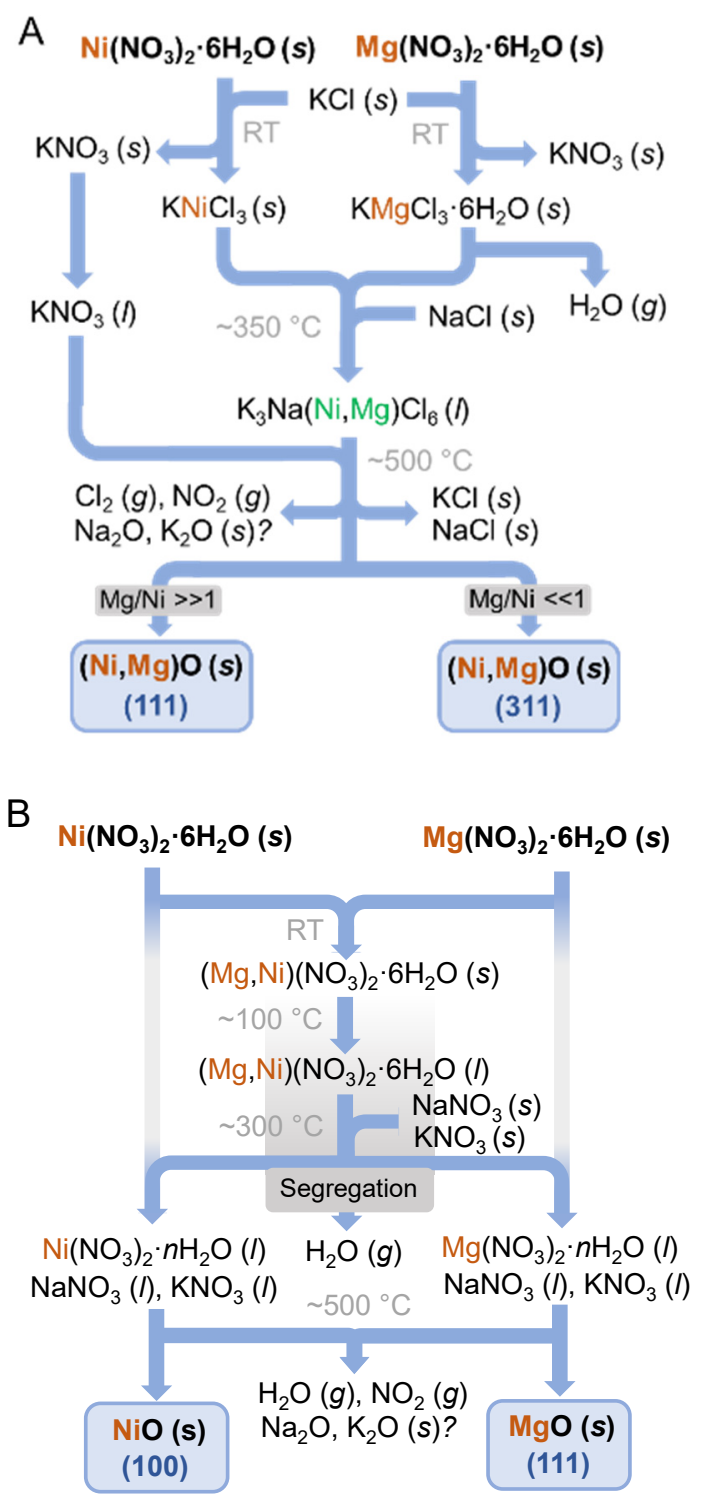

\section{References}

[1] S. Cohen, G. Wollmann, L. Ben-Dor, Y. Marcus, J. Cryst. Growth 2004, 270, 589-592. 